\title{
Multimedia Interaktif Pengenalan Tatacara Sholat Berbasis Animasi 3D Untuk Siswa Tingkat Sekolah Dasar
}

\author{
Eka Sahputra $^{1}$, Yuza Reswan ${ }^{2}$, Ikhwan Baihaqi ${ }^{3}$
}

\author{
${ }^{1,2}$, Dosen Tetap Program Studi Teknik Informatika Universitas Muhammadiyah Bengkulu \\ ${ }^{3}$ Mahasiswa Program Studi Teknik Informatika Universitas Muhammadiyah Bengkulu \\ Alamat Jl. Bali Kota Bengkulu; e-mail: ekasahputra@umb.ac.id¹, yuzareswan@umb.ac.id², iwanbai27@gmail.com³
}

\begin{abstract}
Life is inseparable from the relationship between humans and His God, one of which is worship, namely prayer as the second pillar of Islam. Prayer is one thing that must be done for every Muslim starting from baligh and understanding. Due to the influence of foreign culture which is very rapidly entered into the minds of children, the material about prayer is highly recommended in the era of globalization. The current problem is that the media used are still conventional in nature. Students can only listen to the explanation from the teacher. This sometimes makes students feel bored and lazy to learn because there is no interaction that gives an active role to their students. This learning media uses a picture learning book (which is used as a marker to be scanned by smartphones, into 3-dimensional, 3D animation).
\end{abstract} Keywords: Augmented Reality, Prayer, Marker, Android.

Intisari- Kehidupan tidak terlepas dari hubungan antara manusia dengan Tuhan-Nya, salah satunya cara beribadah yaitu shalat sebagai rukun islam yang ke-2. Shalat merupakan salah satu hal yang wajib dilakukan bagi setiap umat Islam mulai dari baligh dan berakal. Dikarenakan pengaruh budaya asing yang sangat pesat masuk kedalam pemikiran anak-anak, maka materi tentang shalat sangat dianjurkan dalam era globalisasi. Permasalahan yang ada saat ini, media yang digunakan masih bersifat konvensional. Siswa hanya bisa mendengarkan penjelasan dari guru saja. Hal tersebut terkadang membuat siswa merasa bosan dan malas untuk belajar karena tidak adanya interaksi yang memberikan peran aktif kepada siswanya. Media pembelajaran ini menggunakan buku pembelajaran bergambar (yang dijadikan marker untuk dipindai oleh smartphone, menjadi animasi 3 dimensi, 3D).

Kata kunci: Augmented Reality, shalat, marker, android.

\section{PENDAHULUAN}

Metode ceramah dalam proses belajar mengajar sesungguhnya tidak dapat dikatakan suatu metode yang salah. Hal ini dikarenakan model pengajaran ini seperti yang dijelaskan diatas terdiri dari beberapa jenis, yang nantinya dapat dieksploitasi atau dikreasikan menjadi suatu metode ceramah yang menyenangkan, tetapi terdapat beberapa kelemahan pada metode ini, antara lain : Mudah menjadi verbalisme, yang visual menjadi rugi, dan yang auditif (mendengarkan) yang benar-benar menerimanya, bila selalu digunakan dan terlalu digunakan dapat membuat bosan, cenderung membuat siswa pasif [1].

Riset Augmented Reality bertujuan untuk mengembangkan teknologi yang memperbolehkan penggabungan secara real-time terhadap digital content yang dibuat oleh komputer dengan dunia nyata. Augmented Reality memperbolehkan pengguna melihat objek maya dua dimensi atau tiga dimensi yang diproyeksikan terhadap dunia nyata. Teknologi AR ini dapat menyisipkan suatu informasi tertentu ke dalam dunia maya dan menampilkannya di dunia nyata dengan bantuan perlengkapan seperti webcam, komputer, HP Android, maupun kacamata khusus [2].

Maka diperlukan sebuah Teknologi dalam pembelajaran agar lebih menarik seperti Augmented Reality untuk menampilkan objek 3D gerakan sholat sesuai dengan tuntunan dan sunnah nabi Muhammad SAW, dengan harapan teknologi AR ini dapat menjadi media interaktif, menarik, dan dapat lebih mudah dipahami.

\section{LANDASAN TEORI}

A. Konsep Dasar Augmented Reality

Augmented Reality secara umum didefinisikan sebagai menggabungkan dunia nyata dengan dunia virtual untuk dapat berinteraksi secara realtime dalam bentuk tampilan 3D. Augmented reality adalah sebuah istilah untuk lingkungan yang menggabungkan dunia nyata dan dunia virtual yang dibuat oleh komputer sehingga batas antara keduanya menjadi sangat tipis [3]. Virtual objek yang ditambahkan hanya bersifat menambahkan bukan menggantikan objek nyata. Sedangkan tujuan Augmented reality adalah menyederhanakan objek nyata dengan membawa objek maya sehingga informasi tidak hanya untuk pengguna secara langsung melainkan juga untuk setiap pengguna yang berhubungan dengan user interface dari objek nyata.

Sifat Augmented reality yang dapat menampilkan informasi secara realtime sehingga menjadikan Augmented reality banyak dimanfaatkan dalam bidang edukasi, kesehatan, militer, wisata, arsitektur, kesenian, iklan dan masih banyak lagi. Cara kerja augmented reality dalam menambahkan objek virtual ke lingkungan nyata [4].

B. Sholat 
Sholat menurut istilah Syariat Islam adalah ucapan dan perbuatan khusus, diawali dengan takbir dan ditutup dengan salam. Definisi sholat di dalam Kitab Fiqh yang lain pula, secara lughat/bahasa adalah berdo'a, sedangkankan menurut istilah Fiqh adalah "Beberapa perkataan dan perbuatan yang diawali dengan takbir dan diakhiri dengan salam. Sholat lima waktu adalah Rukun Islam yang paling utama setelah dua kalimah syahadat. Dia wajib dilakukan oleh setiap orang muslim laki-laki dan wanita dalam kondisi apapun, baik dalam keadaan aman, takut, dalam keadaan sehat dan sakit, dalam keadaan bermukim atau musafir, dan setiap keadaan memiliki cara khusus dalam pelaksanaannya, sesuai dengan kondisi masing-masing.

\section{Pembelajaran Anak Usia Dini}

Dewasa ini para pendidik sudah mengembangkan metode belajar bagi anak usia dini. Metode belajar sambil bermain diharapkan anak tidak akan merasa bahwa dirinya sedang belajar, hingga membuat kegiatan belajar mengajar lebih luwes dan tidak kaku. Lingkungan belajar dibuat bersahabat dengan anak, sehingga mereka merasa tidak asing [5].

\section{Animasi}

Secara umum animasi adalah rangkaian gambar yang membentuk sebuah gerak. Salah satu keunggulan animasi dibanding media lain seperti gambar statis atau teks adalah kemampuannya untuk menjelaskan perubahan keadaan tiap waktu. Hal ini terutama sangat membantu dalam menjelaskan prosedur dan urutan kejadian .

\section{E. Marker}

Marker adalah suatu gambar yang memiliki pola tertentu yang digunakan untuk menampilkan objek. Gambar yang digunakan sebagai marker harus dengan format .PNG dan .JPG dengan ukuran kurang dari 2MB. Marker yang baik adalah marker yang memiliki banyak detail, memiliki kontras yang baik, serta tidak ada pola yang berulang. Gamabr akan dinilai oleh system, semakin baik feature dari gambar akan semakin baik pula jika digunakan sebagai marker AR. Gambar yang akan dijadikan sebagai marker terlebih dahulu di upload ke database vuforia yang nantinya akan di convert oleh marker engine vuforia. File yang telah di convert akan menghasilkan file dengan format unitypackage.

\section{III.METODE PENELITIAN}

A. Desain Aplikasi

Aplikasi yang dibangun merupakan sebuah aplikasi pembelajaran tuntunan sholat untuk anak. Aplikasi yang menggunakan teknologi augmented reality dapat menampilkan objek 3D dari marker buku panduan sholat. Objek 3D akan muncul ketika mareka AR diarahkan ke marker buku panduan shalat. Objek yang keluar, bergerak sesuai dengan marker yang dituju. Terdapat 10 marker yang dibutuhkan untuk menampilkan 10 gerakan shalat. Hasil aplikasi adalah selain objek 3D gerakan shalat juga akan menghasil output suara. Blok diagram dari aplikasi dapat dilihat pada dibawah ini.

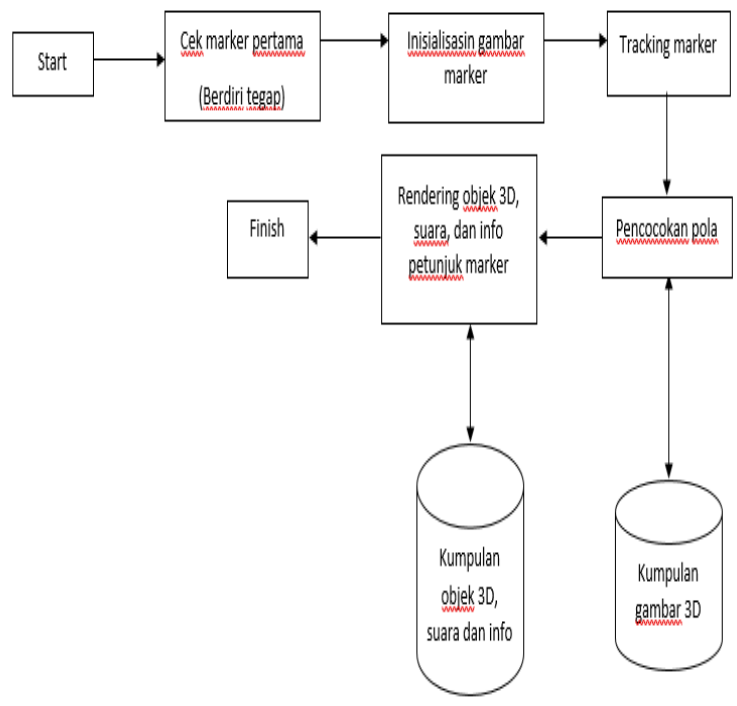

Gambar 1 Blok Diagram Aplikasi Pembelajaran Tuntunan sholat Berbasis Augmented Reality.

B. Desain Proses

1) Cek Market Pertama (Berdiri Tegap)

Rukun sholat yang terahir yaitu tertib. Tertib yang dimaksud adalah tidak mendahulukan satu gerakan dengan gerakan yang lain, atau dengan kata lain berurutan. Oleh karena itu aplikasi pembelajaran gerakan shalat berbasis augmented reality ini akan diterapkan fungsi yang mengatur proses pengurutan. Penerapan proses tersebut berada pada awal aplikasi dijalankan. Ketika awal kamera AR di jalankan. System akan mengecek apakah marker pertama yang dideteksi adalah marker berdiri tegak atau bukan. Jika marker yang ditunjuk oleh kamera AR adalah marker berdiri tegak, maka aplikasi akan menampilkan objek 3D animasi berdiri tegak dan informasi untuk melanjutkan ke marker ke 2. 
2) Inisialisasi

Pada tahap ini dilakukan inisialisasi pada model 3D, inisialisasi animasi, inisialisasi marker, serta inisialisasi info marker.

3) Usecase diagram

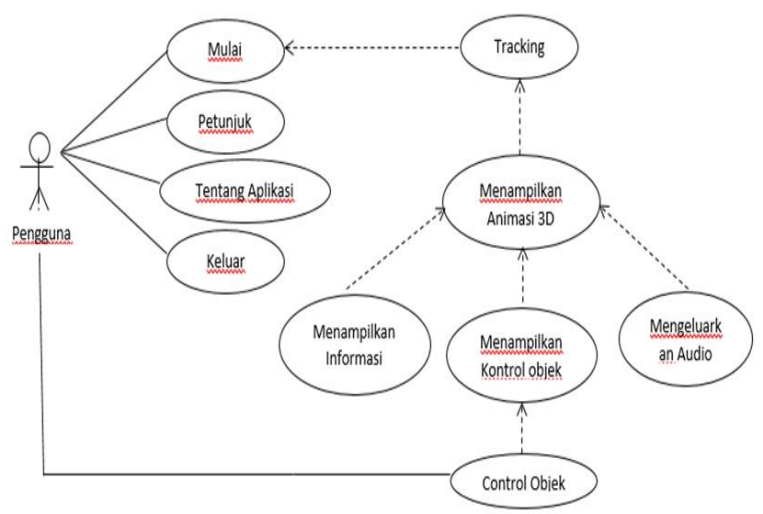

Gambar 2. Usecase Diagram

\section{Pengujian}

Pada tahap ini dilakukan pengujian aplikasi augmented reality buku panduan gerakan Sholat untuk anak. Sebelum aplikasi diujikan ke pengguna, terlebih dahulu dilakukan pengujian aplikasi terhadap device bersistem operasi android. Device yang digunakan untuk pengujian memiliki spesisifikasi yang berbeda-beda. Pengujian selanjutnya yaitu dilakukan untuk menguji masukan ke dalam sistem dan keluaran dari masukan tersebut. Setelah itu akan dilakukan pengujian aplikasi pada user untuk mengetahui keefektifan aplikasi sebagai media pembelajaran pada anak.

\section{IV.HASIL DAN PEMBAHASAN}

Pada Bab ini penulis akan membahas aplikasi multimedia interaktif pengenalan tatacara sholat berbasis animasi 3D untuk siswa tingkat sekolah dasar. Hasil pengembangan berupa produk media pembelajaran Augmented Reality pada platform Android untuk panduan tatacara sholat. Materi pembelajaran tatacara Sholat pada media pembelajaran ini meliputi objek 3D berupa gerakan-gerakan sholat, panduan berupa suara, dan bacaan sholat yang disesuaikan dengan buku tuntunan sholat. Penelitian ini menghasilkan sebuah aplikasi multimedia berbentuk animasi 3D Menggunakan Aplikasi Blander, Vuforia, dan Unity .

\section{A. Implementasi}

Dalam tahapan ini proses implementasi merupakan proses pembuatan pengujian yang akan dilakukan oleh system yang telah dibuat menggunakan aplikasi Blender, vuforia dan unity dengan rancangan yang akan dijelaskan pada urutan dibawah ini.

\section{Modeling Objek}

Pada tahap ini penulis membuat atau memodeling objekobjek yang akan di gunakan dalam pembuatan multimedia interaktif tatacara sholat berbasis animasi 3D.

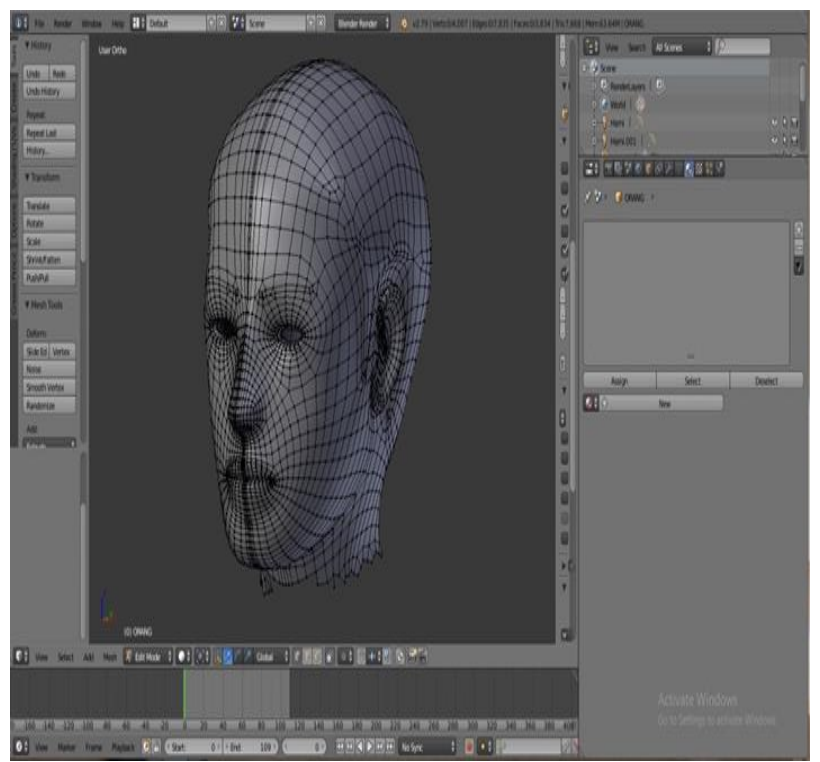

Gambar 3. Modeling

2. Texsturing Objek

Pada proses teksturing ini penulis menambahkan tekstur dan material atau warna yang sesuai dengan objek aslinya sehingga terlihat lebih nyata dan natural.

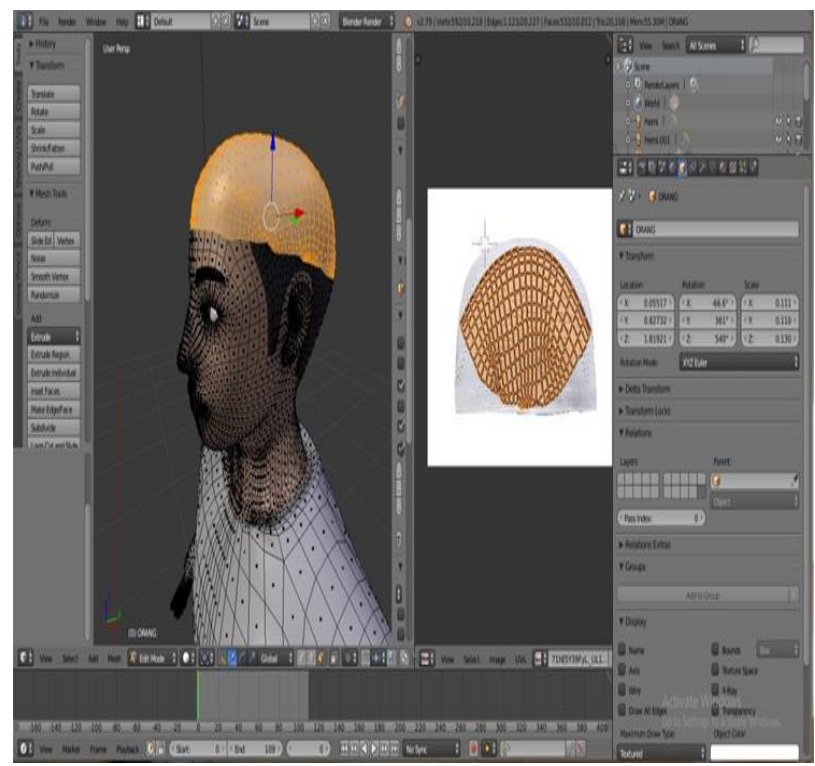

Gambar 4. Proses Texturing 


\section{Animating}

Pada bagian animating penulis membuat animasi camera tracking, pergerakan objek kemera sesuai dengan mengikuti storyboard. Pembuatan animasi sendiri dilakukan secara manual dengan masuk pada tampilan drop sheet dan menambahkan key frame serta mengatur time line agar dapat menyesuaikan pada objek yang di buat.

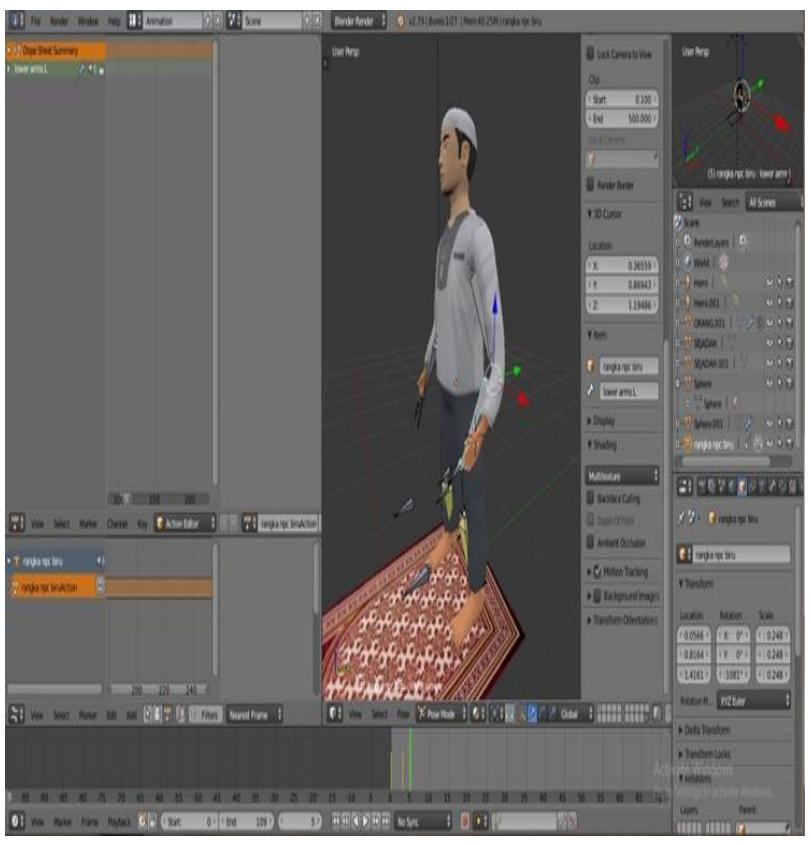

Gambar 5. Proses Animating

\section{Rendering Objek}

Rendering adalah tahap penyatuan keseluruhan proses modeling, texturing, lightning, animating, dan camera operation untuk menjadi satu. Proses rendering dilakukan pada setiap adegan satu demi satu hingga menjadi animasi 3D.

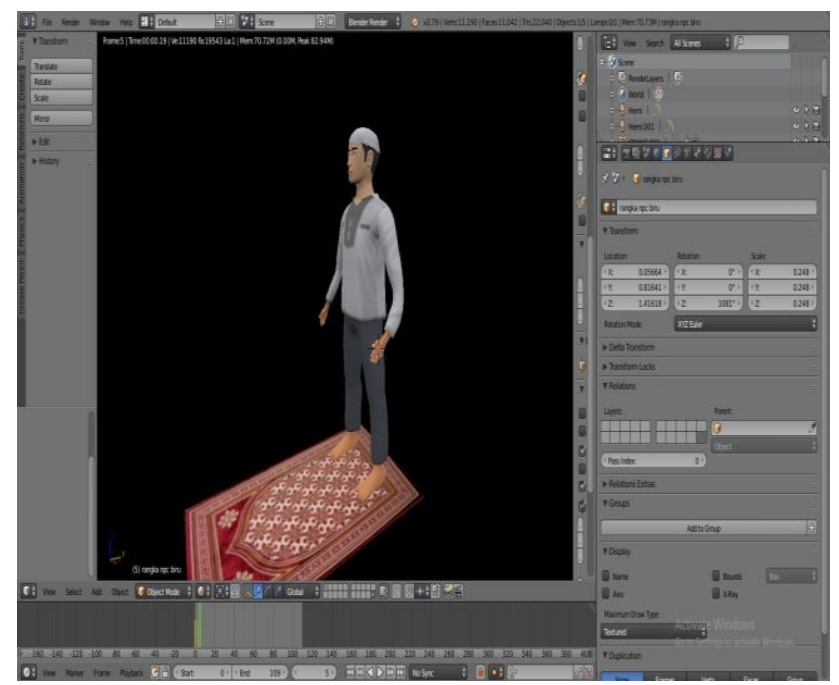

Gambar 6. Proses Rendring

5. Pembuatan APK AR
Pada tahap ini proses pembuatan APK AR dilakukan dengan menggunakan Aplikasi Vuforia yang merupakan Augmented Reality Software Development Kit atau sebuah SDK untuk mobile yang memungkinkan kita untuk membuat sebuah aplikasi Augmented Reality.

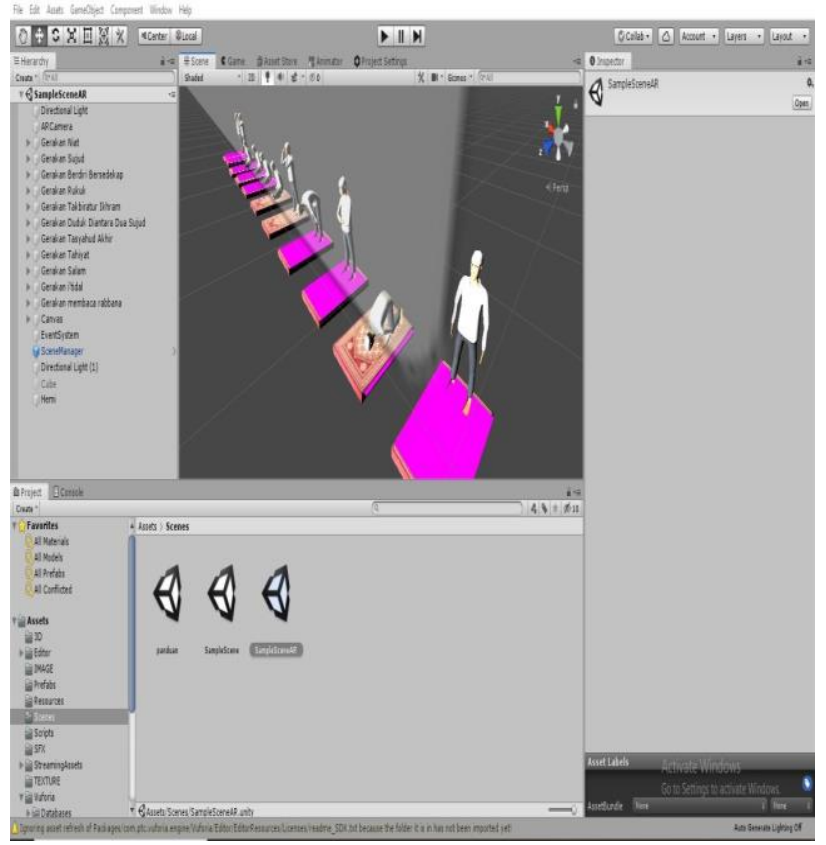

Gambar 7. Proses APK AR

6. Menu Utama AR

Menu utama merupakan tampilan yang akan dilihat user untuk pertama kalinya ketika menjalankan aplikasi. Tampilan menu awal berisi tiga menu utama, yaitu AR sholat, panduan, dan tombol keluar.
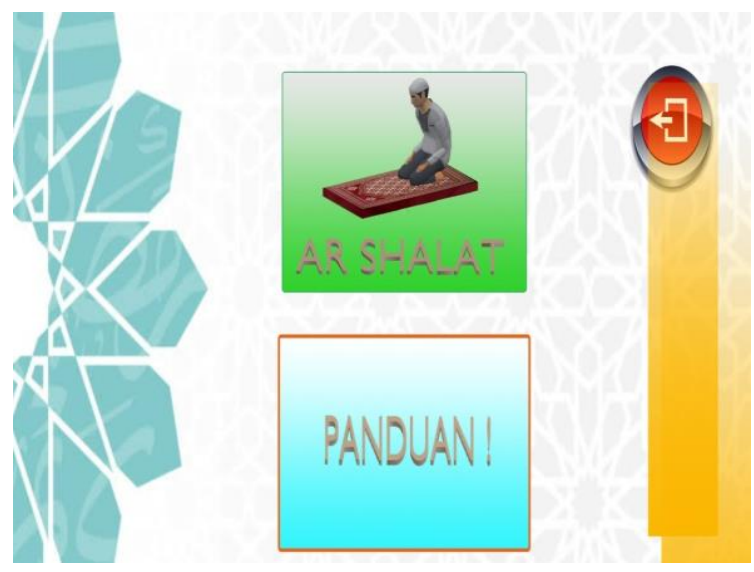

Gambar 8. Menu Utama

7. Kamera AR

Kamera AR yang terdapat pada aplikasi ini berfungsi sebagai media untuk menampilkan objek- objek gerakan sholat yang sudah terdapat titik- titik marker didalam nya. 


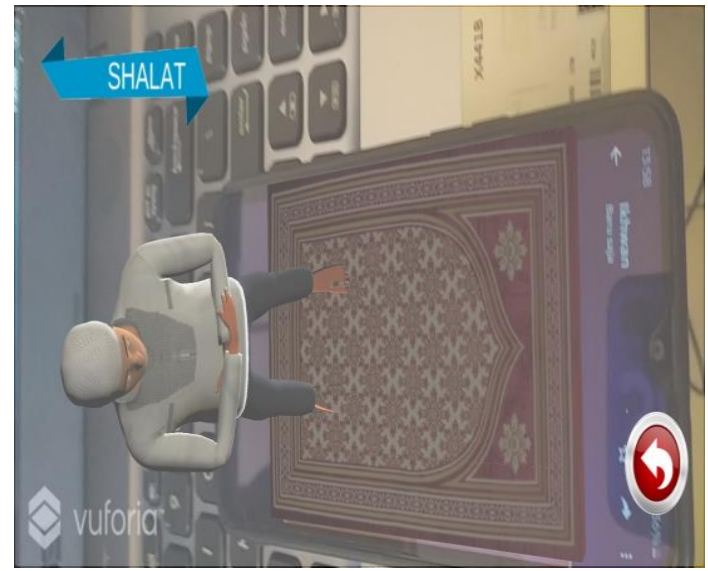

Gambar 8. Kamera AR

B. Pembahasan

Hasil aplikasi ini dibuat untuk memanfaatkan teknologi dalam mengembangkan media pembelajaran khususnya dalam perancangan animasi 3D. Dari hasil penelitian dan implementasi proses pembuatan aplikasi multimedia interaktif tuntunan gerakan sholat berbasis animasi 3D dapat kita bahas pada pembahasan sebagai berikut.

1. Hal pertama yang dilakukan dalam penelitian ini yaitu dengan mengumpulkan data-data dan gambar untuk merancang animasi dan membuat marker, dimana pengumpulan data pada buku tuntunan shalat lima waktu.

2. Implementasi pada penulisan ini telah dijelaskan pada hasil penelitian bahwa, dengan menerapkan tuntunan gerakan sholat berbasis animasi 3D, sehingga kita bisa menerapkan pada metode pembelajaran siswa sekolah dasar.

\section{SIMPULAN}

Dari hasil penelitian ini dapat ditarik kesimpulan sebagai berikut:

1. Dari penelitian ini dapat disimpulkan bahwa tahapantahapan yang dilakukan dalam mengembangkan sebuah multimedia 3D dalam bentuk augmented reality terdiri dari proses modeling, teksturing, ringing, animation, rendering ,pembuatan APK. Hasil dari proses pembuatan animasi kemudian disusun dalam satu kesatuan menggunakan vuforia dan unity sehingga mengasilkan sebuah aplikasi tuntunan gerakan sholat berbasis animasi 3D.

2. Penerapan teknologi Augmented Reality pada tatacara gerakan sholat telah berhasil, yaitu dengan terciptanya aplikasi Multimedia Interaktif Pengenalan Tatacara Sholat Berbasis Animasi 3D Untuk Siswa Tingkat SD.
3. Dengan aplikasi ini, informasi objek menjadi lebih jelas sehingga membuat objek menjadi informatif dan menarik.

4. Dalam pembuatan Aplikasi Augmented Reality pahami terlebih dahulu konsepnya supaya dalam pembuatannya akan lebih mudah, dalam pembuatan animasi diperlukan komponen yang harus disiapkan sebaik mungkin untuk mencegah kekurangan, dalam proses pembuatan animasi dibutuhkan perangkat komputer yang memadai khususnya dalam melakukan animation atau menggerakan objek dan rendering minimalnya processor Intel CoreTM i5-421OU CPU up to $2.70 \mathrm{GHz}$, Memory 4 GB DDR3, HDD $500 \mathrm{~GB}$ Seagate dan VGA Nvidia GeForce 635M-2GB.

\section{DAFTAR PUSAKA}

[1]. Djamarah, Syaiful Bahri dan Aswan Zain. 2013. Strategi Belajar Mengajar.Jakarta: Rineka Cipta.

[2]. Haller, dkk, 2007, Emerging Technologies of Augmented Reality: Interfaces and Design, USA: Idea Group Publishing.

[3]. Sugianto. 2014. Implementasi augmentedreality pada brosur rental mobil CV Asmoro Jati menggunakan metode marker. Semarang: Universitas DIAN NUSWANTORO.

[4]. Hanif, A.2013. Pencarian Tempat Kos dengan Teknologi Augmented Reality Berbasis Smartphone Android. Yogyakarta: Universitas Islam Negeri Sunan Kalijaga

[5]. Sisca, Rahmadonna. 2008. Pengembangan Multimedia Pembelajaran untuk Melatih Kecerdasan Majemuk pada Anak Usia Dini. Tesis Jurusan Teknologi Pembelajaran Program Pascasarjana Universitas negeri Yogyakarta. 